\title{
ОБОСНОВАНИЕ ПРИМЕНЕНИЯ МОДИФИЦИРОВАННОГО ПОДНИЖНЕЧЕЛЮСТНОГО ДОСТУПА ДЛЯ ВСКРЫТИЯ И ДРЕНИРОВАНИЯ ОДОНТОГЕННЫХ ФЛЕГМОН ДНА ПОЛОСТИ РТА
}

\author{
С Щенин А.В. ${ }^{1}$, Громов А.Л. ${ }^{1}$, Иванов С.В. ${ }^{1}$, Губин М.А. ${ }^{2}$, Артюшкова Е.Б. ${ }^{1}$ \\ ${ }^{1}$ Курский государственный медицинский университет (КГМУ) \\ Россия, 305041, Курская область, г. Курск, ул. К. Маркса, д. 3 \\ ${ }^{2}$ Воронежский государственный медицинский университет им. Н.Н. Бурденко (ВГМУ) \\ Россия, 394036, Воронежская обл., г. Воронеж, ул. Студенческая, 10
}

\begin{abstract}
Цель: обоснование применения модифицированного поднижнечелюстного доступа для хирургического лечения одонтогенных флегмон дна полости рта.

Материалы и методы. В исследовании, носившем проспективный характер, участвовали 62 человека. Основная группа: 30 пациентов, средний возраст 46,8土11,8 года, мужчин - 16 (53,3\%), женщин - 14 (46,7\%), у которых применен модифицированный способ оперативного лечения одонтогенных флегмон дна полости рта с частичным рассечением подъязычно-подчелюстного мешка, заявка на изобретение № 2019118924, приоритет от

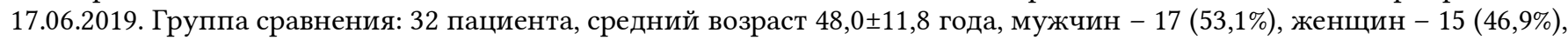
прооперированных с использованием стандартного поднижнечелюстного доступа. Основная группа и группа сравнения сопоставимы по возрасту и полу ( $>0,05)$, характеру фоновой патологии, используемой антибактериальной терапии.

Результаты. Модифицированный доступ позволяет сократить сроки очищения послеоперационной раны с $5,9 \pm 1,9$ суток в группе сравнения, до 4,5 $\pm 1,1$ суток в основной группе $(\mathrm{p}<0,05)$; появления грануляционной ткани с $5,1 \pm 2,0$ суток в группе сравнения, до $3,7 \pm 1,0$ суток в основной группе ( $<0,05)$; наложения вторичного шва с 7,0 $\pm 2,2$ суток в группе сравнения, до $5,8 \pm 1,2$ суток в основной группе $(p<0,05)$. Различий в длительности госпита-

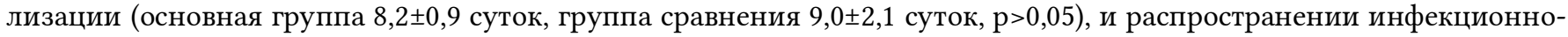
го процесса на соседние пространства (в основной группе в 1 случае, в группе сравнения в 3 случаях, р>0,05) не получено.
\end{abstract}

Заключение. Модифицированный способ лечения флегмон дна полости рта позволяет сократить сроки очищения послеоперационной раны, ускорить появление грануляционной ткани и наложение вторичных швов.

Ключевые слова: флегмона; челюстно-лицевая область; поднижнечелюстной доступ; одонтогенная инфекция; местная форма инфекции.

Щенин Андрей Валентинович - очный аспирант кафедры хирургических болезней № 1, КГМУ, г. Курск. ORCID iD: 0000-0002-9746-7146. E-mail: schenin-92@mail.ru (автор, ответственный за переписку)

Громов Александр Леонидович - канд. мед. наук, доцент кафедры хирургической стоматологии и челюстно-лицевой хирургии, КГМУ, г. Курск. ORCID iD: 0000-0002-4728-6451. E-mail: gromov.alexandr2011@yandex.ru

Иванов Сергей Викторович - д-р. мед. наук, профессор, зав. кафедрой хирургических болезней № 1 , КГМУ, г. Курск. ORCID iD: 0000-0002-2828-7424. E-mail: IvanovSV@kursksmu.net

Губин Михаил Аркадиевич - д-р мед. наук, профессор кафедры стоматологии, ВГМУ, г. Воронеж. E-mail: natasable@yandex.ru

Артюшкова Елена Борисовна - д-р биол. наук, профессор кафедры фармакологии, КГMУ, г. Kypcк. ORCID iD: 0000-0003-3777-6622. E-mail: eartyushkova@mail.ru

Несмотря на свою длительную историю, вопрос лечения одонтогенных флегмон дна полости рта не теряет своей значимости [3]. Связано это со следующими факторами: рост антибиотикорезистентности микроорганизмов из очага гнойно-воспалительного заболевания челюстнолицевой области (ГВЗ ЧЛО), риск стремительного распространения воспалительного процесса по протяжению с последующим развитием жизнеугрожающих септических состояний, таких как медиастинит [1, 9]. Особенно тяжело гнойно-воспалительный процесс протекает на фоне сопутствующей общесоматической патологии: заболеваний сердечно-сосудистой системы, инсулиннезависимого сахарного диабета, хронической обструктивной болезни легких, хронической печеночной и почечной недостаточности, метаболического синдрома [2].

Наряду с решением задач по контролю вышеперечисленных факторов, отягощающих течение ГВЗ ЧЛО, остается открытым вопрос о наиболее подходящем способе местного лечения. На настоящий момент времени предлагаются различные подходы к местному лечению воспалительных процессов глубоких клетчаточных пространств шеи и головы. Общепринятое хирургическое лечение включает широкое вскрытие, дренирование инфекционного очага с последующими перевязками и наложением вторичных швов после очищения послеоперационной раны $[5,7]$. Другим подходом к решению данной проблемы является дренирование 
клетчаточных пространств челюстно-лицевой области через относительно небольшие разрезы с применением эндоскопической хирургической техники и системы закрытого аспирационного дренирования, подразумевающей герметичное ушивание раны на аспирационном дренаже. Такой подход позволяет отказаться от использования вторичного шва, оперативный доступ наименее травматичен, что обусловливает косметичность послеоперационного рубца и укорочение реабилитационного периода [3, 11]. Однако очевидно, что подобный подход применим далеко не во всех клинических ситуациях, так как требует наличия видеоэндоскопической установки в операционной и подготовленного персонала. Наличие же гнилостной анаэробной инфекции при ГВЗ ЧЛО само по себе требует ведения послеоперационных ран у таких пациентов открытым способом, позволяющим лучшим образом осуществить при необходимости ревизию пораженных клетчаточных пространств.

Наряду со сложностью лечения самого гнойно-воспалительного заболевания челюстнолицевой области, в настоящее время пациенты, поступающие на стационарное лечение в отделения челюстно-лицевой хирургии, предъявляют повышенные требования к косметическим и функциональным характеристикам послеоперационного рубца, его незаметности. По данным некоторых источников, судебные иски пациентов по поводу неудовлетворенности внешним видом рубца могут возникать в 44 из 98 случаев после операций на коже [8]. Этот факт необходимо учитывать при выборе формы линии разреза кожи, его анатомическом расположении и отношении к линиям напряжения растянутой кожи (линиям Лангера) [7].

Целью исследования является обоснование применения модифицированного поднижнечелюстного доступа для хирургического лечения одонтогенных флегмон дна полости рта.

\section{МАТЕРИАЛЫ И МЕТОДЫ ИССЛЕДОВАНИЯ}

Для лечения пациентов с ГВЗ ЧЛО предложен модифицированный способ лечения флегмон дна полости рта с частичным рассечением подъязычно-подчелюстного мешка (заявка на изобретение «Способ оперативного лечения одонтогенных флегмон дна полости рта с частичным рассечением подъязычно-подчелюстного мешка» № 2019118924, приоритет от 17.06.2019). В качестве прототипа был использован способ лечения разлитых и гнилостнонекротических флегмон дна полости рта, предложенный А.А. Чучуновым и соавторами [6]: под общим обезболиванием после двукратной обработки операционного поля проводят воротникообразный разрез кожи в правой и левой поднижнечелюстных, подподбородочной областях. Рассекают подкожно-жировую клетчатку, подкожную мышцу, поверхностный листок собственной фасции шеи. Путем расслаивания тканей проникают в правое и левое поднижнечелюстные, крыловидно-нижнечелюстные, окологлоточные пространства, к корню языка. После чего проводят рассечение челюстноподъязычной мышцы на всем протяжении до 47 и 37 зубов справа и слева, и передних брюшек правой и левой двубрюшной мышц. Кроме этого при гнилостно-некротических флегмонах дополнительно пересекают и лигируют правые и левые лицевые артерии и вены с их последующим прошиванием к окружающим тканям, а челюстно-подъязычную мышцу дополнительно рассекают до углов нижней челюсти справа и слева.

На рисунке 1 представлен традиционный поднижнечелюстной доступ к флегмонам дна полости рта. Доступ характеризуется отсутствием рассечения и ревизии подъязычноподчелюстного мешка по верхнему краю поднижнечелюстной слюнной железы, что создает недостаточно приемлемые условия для дренирования флегмоны.

Предлагаемый нами способ дополнен частичным рассечением подъязычноподчелюстного мешка [4] с целью оптимизации условий для дренирования флегмоны и скорейшего очищения послеоперационной раны. Описание модифицированного способа лечения флегмон дна полости рта с частичным рассечением подъязычно-подчелюстного мешка: выполняется зигзагообразный, нелинейный разрез кожи с длинами составляющих зигзаг линий около 2 см, расположенных под углом $120^{\circ}$ к друг другу и параллельно краю нижней челюсти в правой и левой поднижнечелюстных областях, на 3 см ниже края челюсти с сохранением кожных перемычек между подчелюстными и подподбородочной областями. Волнистая форма послеоперационной раны позволяет придать линиям, составляющим разрез, направления, отличающиеся от направления вектора действующих на рубец растягивающих сил мышц. Кроме того, обозначенное расстояние 3 см между краем нижней челюсти и операционной раной уменьшает вероятность травмы краевой ветви лицевого нерва. После осуществления доступа выполняют частичное рассечение подъязычно-подчелюстного мешка непосредственно в промежутке между подчелюстной слюнной железой и прилежащему к подчелюстной слюнной железе участку тела нижней челюсти, 


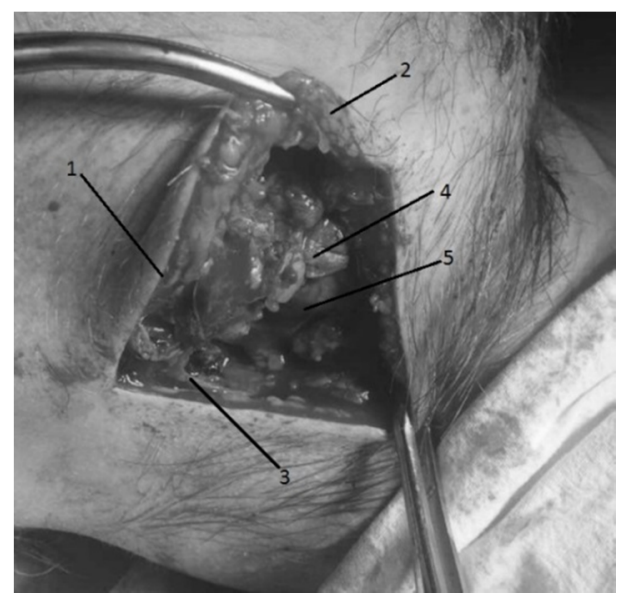

Рис. 1. Традиционный доступ для вскрытия и дренирования флегмоны дна полости рта.

Примечание: 1 - линия разреза кожи; 2 - подкожная жировая клетчатка; 3 - поверхностная фасция шеи, окутывающая подкожную мышщу; 4 - поверхностный листок собственной фасции шеи, расщепление которого образует подъязычно-подчелюстной мешок; 5 - нижний полюс поднижнечелюстной слюнной железы, мешает ревизии пространства между нижней челюстью и поднижнечелюстной слюнной железой.

Fig. 1. Traditional approach for incision and drainage of odontogenic infection of the floor of the mouth.

Note: 1 . - skin incision line; 2 - subcutaneous fat; 3 - superficial fascia of the neck enveloping the platysma muscle; 4 - superficial sheet of the neck fascia, the cleavage of which forms the sublingual-submandibular sac; 5 - the lower pole of the submandibular salivary gland, that interferes with the complete revision of the space between the mandible and the submandibular salivary gland.

на протяжении 3 см. Через данный разрез раздвигают волокна челюстно-подъязычной мышцы, осуществляя тем самым доступ к клетчаточным пространствам дна полости рта, дополнительно осуществляется дренирование книзу и кзади от слюнной железы. Выполняется пальцевая ревизия перечисленных клетчаточных пространств. Послеоперационная рана обильно промывается водными растворами местных антисептиков (перекись водорода 3\%, хлоргексидин 0,05\%), дренируется двухпросветными силиконовыми трубками, накладывается рыхлая марлевая асептическая повязка с растворами антисептиков либо мазевая повязка.

Преимуществом предлагаемого метода является то, что подъязычно-подчелюстной мешок рассекается непосредственно в промежутке между нижним краем нижней челюсти и поднижнечелюстной слюнной железой. Данный прием обеспечивает кратчайший доступ к скоплению экссудата, которое при инфекционном процессе одонтогенной этиологии локализуется в непосредственной близости к нижней челюсти. Следовательно, при уменьшении глубины операционного доступа улучшаются условия для дренирования очага одонтогенной инфекции. Немаловажным положительным моментом предложенного доступа является то, что практически всегда оперативное вмешательство осуществляется под местной анестезией.

Исследование носит проспективный характер. Отобрано 62 пациента, находившихся на стационарном лечении в отделении челюстно-лицевой хирургии БМУ «Курская областная клиническая больница» по поводу ГВЗ ЧЛО с апреля 2018 г. по август 2019 г. Для оценки тяжести состояния пациентов применялась балльная шкала qSOFA, включающая оценку трех показателей организма, дающих в сумме 3 балла: систолическое артериальное давление $\leq 100$ мм рт. ст. - 1 балл, частота дыхательных движений $\geq 22$ в минуту - 1 балл, угнетение сознания ниже 14 баллов по шкале комы Глазго 1 балл. В соответствии с положениями соглашения Сепсис-3, пациенты, имеющие $\geq 2$ балла по данной шкале, с большей вероятностью будут иметь септический процесс и более длительное время нахождения в отделении реанимации и интенсивной терапии в процессе лечения [10].

Критерии включения: местная форма одонтогенной гнойной инфекции (отсутствие органной недостаточности); флегмона в пределах 1-4 клетчаточных пространств; qSOFA<2 баллов.

Критерии исключения: сепсис (органная недостаточность); распространенная флегмона с вовлечением более 4 клетчаточных пространств; флегмона шеи, медиастинит; декомпенсированная фоновая патология, qSOFA $\geq 2$ балла.

Для статистической обработки полученных данных были использованы: t-критерий Стьюдента для двух независимых переменных, точный двусторонний критерий Фишера Р для таблиц сопряженности. Сравниваемые группы имели нормальное распределение. Статистический анализ данных выполнялся в приложении STATISTICA 10 для персонального компьютера с операционной системой Windows 7. 
Пациенты были разделены на 2 группы: основную и сравнения. Разработанный нами доступ был применен у 30 пациентов, которые составили основную группу. Средний возраст $(\mathrm{M} \pm \mathrm{s})-46,9 \pm 11,8$ лет, мужчин - 16 (53,3\%), женщин - 14 (46,7\%).

Основная и группа сравнения не различались по среднему количеству вовлеченных в воспалительный процесс пространств. В группе сравнения количество пораженных пространств составило в среднем $2,2 \pm 1,0$, в основной группе $-2,0 \pm 0,9$. Различия не были статистически достоверными ( $>0,05)$.

Группа сравнения - 32 пациента, получавшие лечение по традиционной схеме с дренированием флегмон дна полости рта через стандартный поднижнечелюстной доступ. Пациенты были отобраны для исследования в случайном порядке, с целью обеспечения адекватного объема выборки и разделения на группы в зависимости от применяемого способа лечения: модифицированный или традиционный. Средний

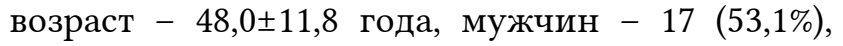
женщин - 15 (46,9\%).

В основной группе фоновая патология представлена заболеваниями сердечно-сосудистой системы (гипертоническая болезнь, хроническая сердечная недостаточность, ишемическая болезнь сердца) у 13 (43,3\%) пациентов, заболеваниями дыхательной системы (хронический бронхит, хронический тонзиллит) у 4 (13,3\%) пациентов, заболеваниями эндокринной системы (сахарный диабет 2 типа) у 4 (13,3\%) пациентов, заболеваниями пищеварительной системы (язвенная болезнь желудка, хронический гастрит) у $6(20,0 \%)$ пациентов. Хроническая алкогольная интоксикация была выявлена у 2 (6,7\%), отсутствие хронических системных заболеваний у $8(26,7 \%)$ пациентов основной группы.

В группе сравнения фоновая патология представлена заболеваниями сердечнососудистой системы (гипертоническая болезнь, хроническая сердечная недостаточность, ишемическая болезнь сердца) у $15(46,9 \%)$ пациентов, заболеваниями дыхательной системы (хронический бронхит, хронический тонзиллит) у 3 (9,4\%) пациентов, заболеваниями эндокринной системы (сахарный диабет 2 типа) у $6(18,8 \%)$ пациентов, заболеваниями пищеварительной системы (язвенная болезнь желудка, хронический гастрит) у $4(12,5 \%)$ пациентов. Хроническая алкогольная интоксикация была выявлена у 2 (6,7\%), отсутствие хронических системных заболеваний у $9(28,1 \%)$ пациентов основной группы.

Основная группа и группа сравнения сопоставимы по возрасту и полу, фактору наличия и характеру фоновой патологии $(\mathrm{p}>0,05)$.
Пациентам обеих групп при поступлении в отделение челюстно-лицевой хирургии назначалась двухкомпонентная парентеральная антибактериальная терапия антибиотиками группы аминогликозидов (амикацин) и группы цефалоспоринов третьего поколения (цефтриаксон или цефотаксим).

Оперативный доступ у пациентов обеих групп ограничивался созданием разреза в поднижнечелюстной области, соответствующей стороне локализации воспалительного процесса, на всю длину воспалительного инфильтрата, что составляло от 5,0 до 15,0 сантиметров. В случае вовлечения в воспалительный процесс клетчаточных пространств дна полости рта с обеих сторон, разрезы для вскрытия и дренирования флегмоны располагались в левой и правой поднижнечелюстных областях с оставлением кожной перемычки в подподбородочной области.

При оперативном вмешательстве и последующих перевязках обработка послеоперационной раны осуществлялась водным раствором перекиси водорода 3\%, вносимым в рану на марлевых салфетках и тупферах, пульсирующей струей водного раствора хлоргексидина биглюконата $0,05 \%$.

После осуществления одного из вышеописанных способов вскрытия и дренирования очага ГВЗ ЧЛО выполнялась установка двухпросветных перфорированных силиконовых дренажей с диаметром от 9 до 11 мм, по одному в каждое вскрытое клетчаточное пространство, до 4 штук в общей сложности. Дренажи фиксировались узловатыми швами из нерезорбируемого шовного материала лавсан номер 3/0 к краю кожного разреза. Раневая полость после оперативного вмешательства рыхло тампонировалась марлевыми салфетками, пропитанными водным раствором натрия хлорида 10\%. Смена салфеток с указанным осмотически активным раствором выполнялась до прекращения поступления раневого отделяемого. С целью ускорения отторжения очагов некротизированных тканей в основной группе и группе сравнения в рану вводились салфетки, пропитанные раствором ферментного препарата хемотрипсин.

Вывод об окончательном очищении послеоперационной раны от экссудата и некротически измененных тканей, о ее переходе в стадию пролиферации в обеих группах делался на основании внешнего вида грануляционной ткани. Жизнеспособная грануляционная ткань должна покрывать равномерно всю раневую поверхность, при туалете раны активно кровоточить. Сами грануляции характеризуются сочным красным цветом, без налета некротических тканей, что продемонстрировано на рисунке 2. 


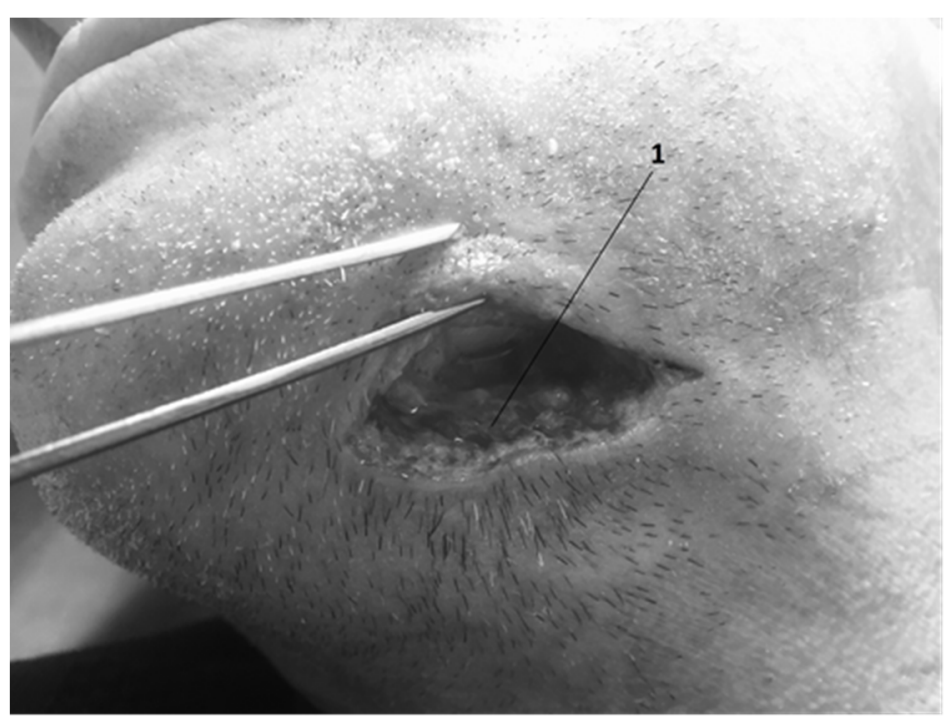

Рис. 2. Вид гранулирующей послеоперационной раны.

Примечание: 1 - жизнеспособная грануляционная ткань, равномерно покрывающая раневую поверхность и активно кровоточащая при смене повязки.

Fig. 2. Appearance of granulating postsurgical wound.

Note: 1 - viable granulation tissue which is widely covering the wound surface and actively bleeding when changing the bandage.

Таблица 1

Table 1

Результаты использования модифицированного поднижнечелюстного доступа для лечения одонтогенных флегмон дна полости рта

Results of the use of the modified submandibular approach for treating odontogenic infection of the floor of the mouth

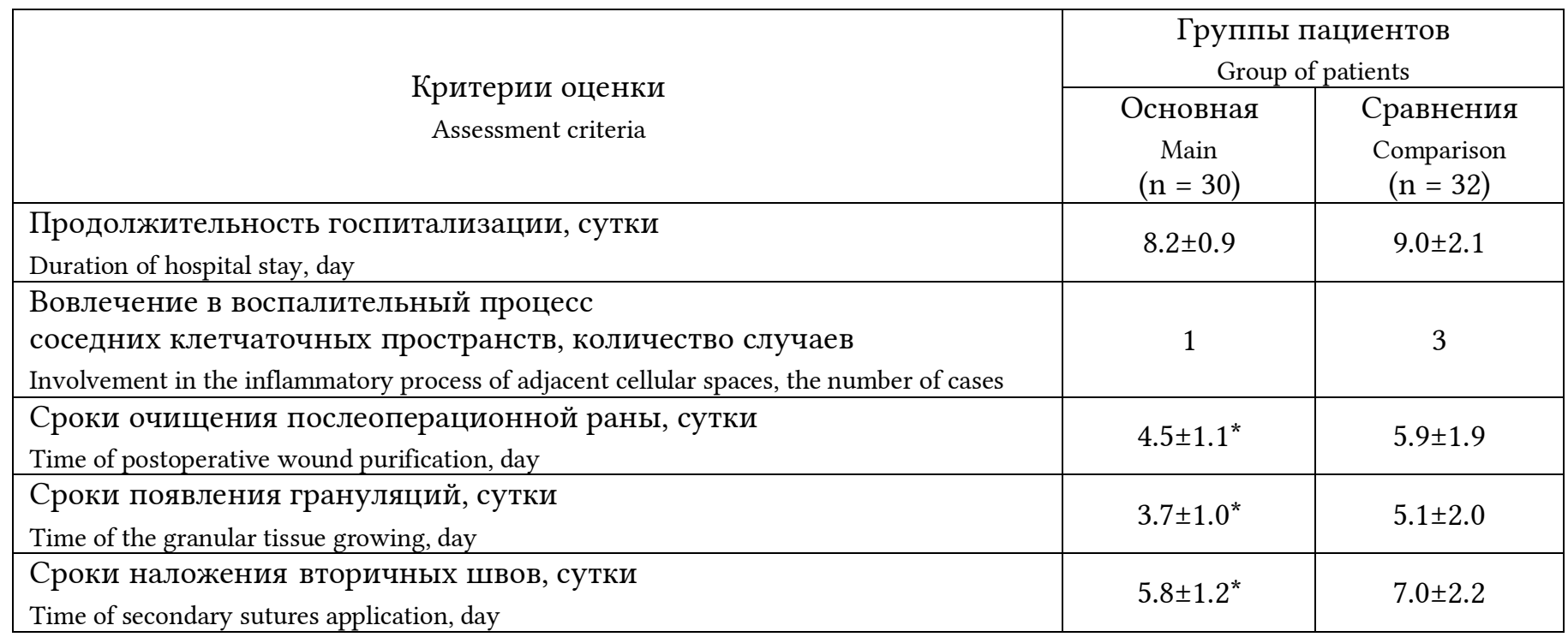

Примечание: *p < 0,05 - различия статистически значимы, $\mathrm{n}$ - количество пациентов, включенных в группу.

Note: * $\mathrm{p}<0.05$ - the differences are statistically significant, $\mathrm{n}$ - number of patients included in the group.

\section{РЕЗУЛЬТАТЫ ИССЛЕДОВАНИЯ И ИХ ОБСУЖДЕНИЕ}

Результаты исследования представлены в таблице 1 .

Разница в продолжительности госпитализации пациентов основной группы и группы сравнения составила около 1 суток, что не является статистически значимым различием $(\mathrm{p}>0,05)$. Однако имеется тенденция к уменьшению сроков стационарного лечения пациентов, прооперированных модифицированным методом $(\mathrm{p}=0,06)$. 


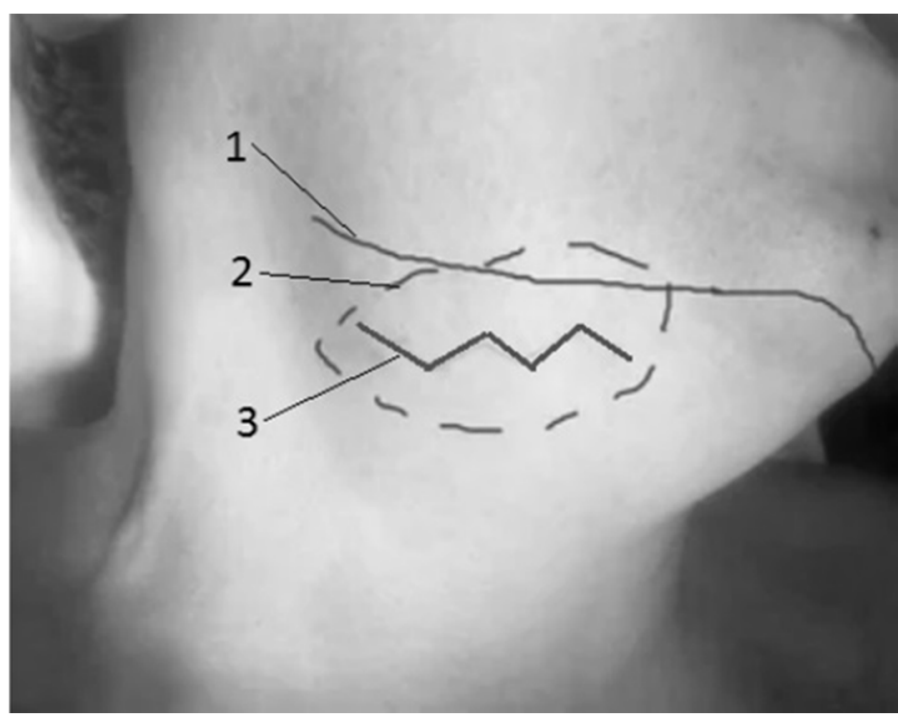

Рис. 3. Модифицированный доступ для вскрытия и дренирования флегмоны дна полости рта.

Примечание: предоперационная разметка: 1 - проекция нижнего края нижней челюсти; 2 - границы воспалительного инфильтрата; 3 - линия зигзагообразного разреза кожи по типу «ломаной линии».

Fig. 3. Modified submandibular approach for incision and drainage of odontogenic infection of the floor of the mouth.

Note: preoperative marking: 1 - a projection of the lower edge of the mandible; 2 - borders of the inflammatory infiltrate; 3 - a line of the Z-like incision of the skin by "broken line"- type.

Также не выявлено влияния модифицированного доступа на распространение гнойновоспалительного процесса $(\mathrm{p}>0,05)$.

Однако стоит сказать, что предлагаемый нами способ повлиял на такие немаловажные показатели лечения, как сроки очищения послеоперационной раны и появления грануляций, сроки наложения вторичного шва.

Применение модифицированного доступа позволило уменьшить сроки длительности очищения послеоперационной раны от гноя и некротических тканей в среднем на 1,4 суток в основной группе, значения статистически достоверны $(\mathrm{p}<0,05)$.

Первые признаки появления грануляционной ткани в послеоперационной ране наблюдались на $3,7 \pm 1,0$ сутки в основной группе, что раньше в среднем на 1,4 суток при сопоставлении с группой сравнения, достоверно при этом отличаясь $(\mathrm{p}<0,05)$.

Применение модифицированного доступа позволило сократить срок наложения вторичного шва на послеоперационную рану в основной группе по сравнению с контрольной группой в среднем на 1,2 суток. Различия статистически достоверны $(\mathrm{p}<0,05)$. Клинический случай, представленный ниже, демонстрирует преимущества предложенного нами способа.

Пациент Ш., 39 лет, госпитализирован в отделение челюстно-лицевой хирургии Курской областной клинической больницы в экстренном порядке 27.02.2019 с диагнозом: Одонтогенная флегмона крыловидно-челюстного, под- нижнечелюстного, окологлоточного пространств справа от зуба 48. При поступлении предъявлял жалобы на повышение температуры тела, боль при накусывании на «зуб мудрости» на нижней челюсти справа, затруднение глотания и открывания рта, появившиеся 3 дня назад. Показатели жизненно важных систем органов при поступлении в стационар: артериальное давление 140/90 мм рт. ст., частота пульса 78 ударов в минуту, частота дыхания 18 в минуту. Сознание ясное, по шкале комы Глазго 15 баллов. 0 баллов по шкале qSOFA. Status localis: конфигурация лица изменена за счет умеренно выраженного, напряженного, резко болезненного при пальпации отека правой поднижнечелюстной области, ограничение открывания рта до 1 см. В полости рта: язык обложен налетом, гигиена полости рта неудовлетворительная. Зуб 48 - коронка зуба значительно разрушена кариозным процессом, перкуссия зуба резко болезненная. Крыловидно-челюстная складка справа резко гиперемирована, при пальпации резко болезненная. Выполнен необходимый минимум дополнительных исследований. Лабораторные показатели при поступлении: клинический анализ крови - эритроциты $4,86^{*} 10^{12} /$ л, гемоглобин $151 \mathrm{r} / л$, тромбоциты $120^{*} 10^{9} /$ л, лейкоциты $9,2^{*} 10^{9} /$ л, скорость оседания эритроцитов $35 \mathrm{~mm} /$ час; биохимический анализ крови - общий белок крови 76,8 г/л, билирубин общий 23,8 мкмоль/л (прямой 10,2 мкмоль/л, непрямой 13,6 мкмоль/л), глюкоза крови 4,1 ммоль/л. 


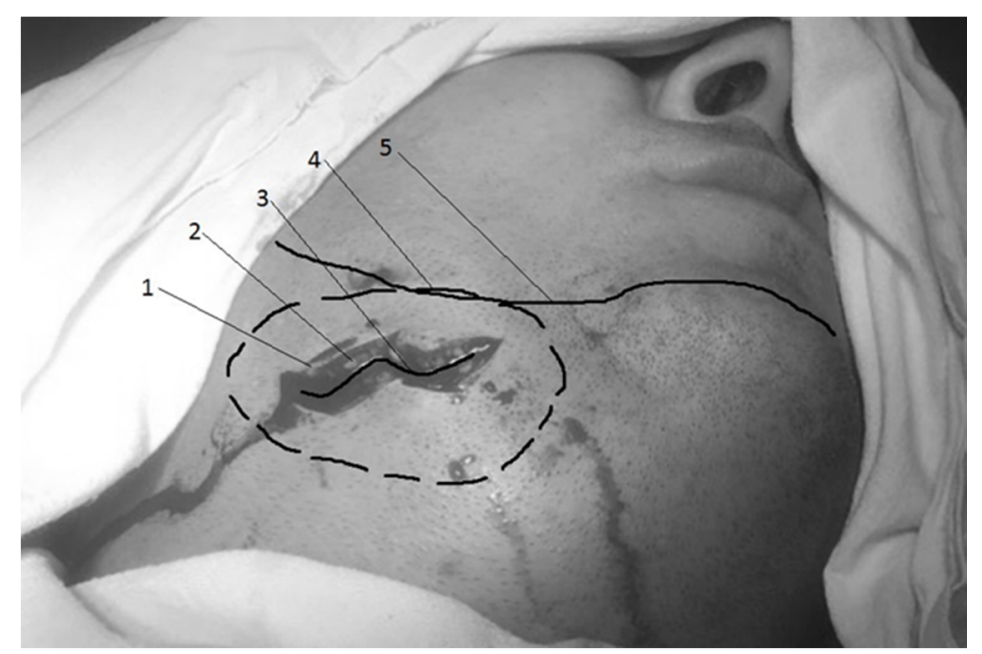

Рис. 4. Модифицированный доступ для вскрытия и дренирования флегмоны дна полости рта.

Примечание: выполненный доступ: 1 - край разреза кожи; 2 - подкожная жировая клетчатка, поверхностная фасция шеи; 3 - подъязычно-поднижнечелюстной мешок в промежутке между нижним краем нижней челюсти и верхним полюсом поднижнечелюстной слюнной железы; 4 - границы воспалительного инфильтрата; 5 - нижний край нижней челюсти.

Fig. 4. Modified submandibular approach for incision and drainage of odontogenic infection of the floor of the mouth.

Note: performed approach: 1 - the edge of the skin incision; 2 - subcutaneous fat, superficial fascia of the neck; 3 - sublingualsubmandibular sac between the lower edge of the mandible and the upper pole of the submandibular salivary gland; 4 - the borders of inflammatory infiltration; 5 - the lower edge of the mandible.

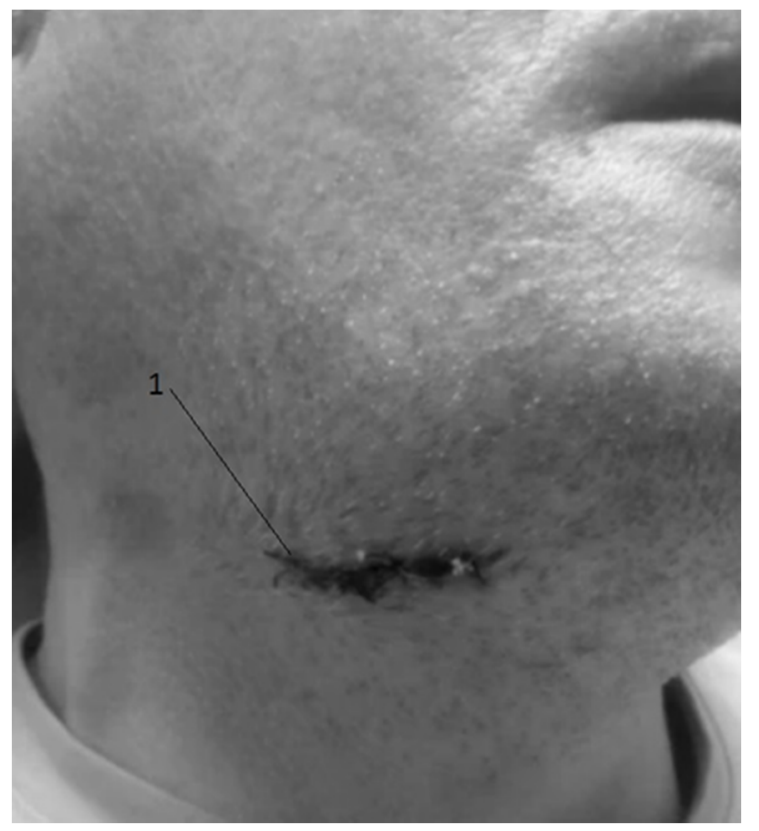

Рис. 5. Вид послеоперационной раны на 14 сутки от момента госпитализации.

Примечание: 1 - линия формирующегося послеоперационного рубца.

Fig. 5. Appearance of the postoperative wound on the 14th day from the moment of hospitalization.

Note: 1 - a line of postoperative scar formation.

Принято решение о вскрытии и дренировании флегмоны через модифицированный поднижнечелюстной доступ, удаление причинного зуба 48 под местной анестезией в условиях экстренной операционной. На рисунке 3 продемонстрирована предоперационная разметка.

Во время операции выполнен зигзагообразный разрез кожи по линии разметки, тупым способом расслоена подкожная жировая клет- чатка, послойно рассечены: подкожная мышца шеи с покрывающим ее листком поверхностной фасции шеи, подъязычно-поднижнечелюстной мешок в промежутке между нижним краем нижней челюсти и верхним полюсом поднижнечелюстной слюнной железы в правой поднижнечелюстной области. Лицевые артерия и вена, краевая ветвь лицевого нерва отведены с массивом мягких тканей вверх и кзади. Через 
полученный доступ выполнена пальцевая ревизия, получено жидкое гнойное отделяемое с неприятным запахом из крыловидно-челюстного, поднижнечелюстного, окологлоточного пространств, взято на бактериологический посев. Послеоперационная рана обильно промыта растворами антисептиков, во вскрытые пространства установлены двухпросветные трубчатые дренажи, наложена марлевая повязка с гипертоническим раствором хлорида натрия. Операционный доступ представлен на рисунке 4.

Послеоперационный период протекал без осложнений, выполнялись перевязки с растворами антисептиков, осмотически активных препартов, двухкомпонентная антибактериальная терапия (растворы антибиотиков амикацин, цефотаксим внутримышечно). Посев раневого отделяемого выявил культуру Staph. haemolyticus, чувствительную $к$ назначенным антибиотикам. Рост первых грануляций отмечался к 3 суткам после вскрытия флегмоны, послеоперационная рана полностью очистилась на 4 сутки. Вторичные швы наложены на 6 сутки стационарного лечения. Пациент выписан с улучшением, в удовлетворительном состоянии на амбулаторное лечение на 8 сутки после госпитализации.

На рисунке 5 продемонстрирован вид послеоперационной раны перед снятием вторичных швов на 14 сутки от момента госпитализации. Линии формирующегося рубца отличаются от направления вектора действующих на рубец растягивающих сил мышц.

Предлагаемый нами модифицированный способ вскрытия и дренирования флегмон дна полости рта имеет следующие преимущества: достоверно сокращаются сроки очищения послеоперационной раны, что благоприятно сказывается на появлении и росте грануляционной ткани. Эти условия создают предпосылки для скорейшего наложения ранних вторичных швов.

В целом проблема применения модифицированной методики хирургического лечения ГВЗ ЧЛО требует дальнейшего лечения и разработки.

\section{КОНФЛИКТ ИНТЕРЕСОВ}

Авторы декларируют отсутствие явных и потенциальных конфликтов интересов, связанных с публикацией настоящей статьи.

\section{ЛИЧНЫЙ ВКЛАД АВТОРОВ}

Щенин А.В., Громов А.Л. - анализ и интерпретация данных. Иванов С.В. - разработка концепции и дизайна статьи, обоснование рукописи и проверка критически важного интеллектуального содержания, окончательное утверждение для публикации руко- писи. Губин М.А. - разработка концепции и дизайна статьи, обоснование рукописи и проверка критически важного интеллектуального содержания. Артюшкова Е.Б. - разработка концепции и дизайна статьи.

\section{ИСТОЧНИКИ ФИНАНСИРОВАНИЯ}

Авторы заявляют об отсутствии финансирования.

\section{СООТВЕТСТВИЕ ПРИНЦИПАМ ЭТИКИ}

Протокол исследования одобрен Региональным этическим комитетом. Протокол заседания Регионального этического комитета № 11 от 10.12.2018. Участники подписывали информированное согласие перед участием в исследовании.

\section{ЛИТЕРАТУРA/REFERENCES}

1. Афиногенова А.Г., Ворошилова Т.М., Афиногенов Г.Е., Мадай Д.Ю. Оценка эффективности нового ингибитора металло-беталактамазы в условиях модельной системы in vitro. Инфекция и иммунитет. 2016; 6(4):335-344 [Afinogenova A.G., Voroshilova T.M., Afinogenov G.E., Maday D.Yu. The new metall-betalactamase's inhibitor efficacy in a model system in vitro. Infektsiya $i$ immunitet. 2016; 6(4):335-344 (in Russ.)] DOI: 10.15789/2220-7619-2016-4-335-344

2. Громов А.Л., Губин М.А., Иванов С.В., Тишков Д.С., Щенин А.В. Дисфункция эндотелия у пациентов с одонтогенными воспалительными заболеваниями челюстно-лицевой области. Институт стоматологии. 2019; 1(82):90-91 [Gromov A.L., Gubin M.A., Ivanov S.V., Tishkov D.S., Shchenin A.V. Endothelial dysfunction in patients with odontogenic inflammatory diseases of maxillofacial region. The Dental Institute. 2019; 1(82):90-91 (in Russ.)]

3. Лишов Е.В., Харитонов А.А., Путинцев А.М. Особенности хирургического лечения анаэробных инфекций глубоких пространств шеи, осложненных медиастинитом. Acta biomedica scientifica. 2017; 2(6-112):130-133 [Lishov E.V., Kharitonov A.A., Putintsev A.M. Surgical treatment of anaerobic deep neck infection complicated by mediastinitis. Acta biomedica scientifica. 2017; 2(6-112):130-133. (in Russ.)] DOI: $10.12737 /$ article_5a0a8b9552aa85.61732968

4. Лойт А.А., Каюков А.В. Хирургическая анатомия головы и шеи: краткое руководство. СанктПетербург: Питер, 2002. 224 c. [Loit A.A., Kayukov A.V. Surgical anatomy of the head and neck: a brief guide. St. Petersburg: Piter, 2002. 224 p. (in Russ.)]

5. Соловьев М.М., Большаков О.П., Галецкий Д.В. Гнойно-воспалительные заболевания головы и шеи: Этиология, патогенез, клиника, лечение. 3-е изд. стереотип. Москва: Умный доктор, 2016. 192 с. [Soloviev M. M., Bolshakov O.P., Galetsky D.V. Pyoinflammatory diseases of the head and neck: Etiology, 
pathogenesis, clinic, treatment. $3^{\text {rd }}$ ed., stereotyp. Moscow: Umnyy doktor, 2016. 192 p. (in Russ.)]

6. Чучунов А.А., Левенец А.А., Крикун С.В., Николаев О.В., Бобкова О.В., авторы. Красноярская государственная медицинская академия, патентообладатель. Способ оперативного лечения разлитых и гнилостно-некротических флегмон дна полости рта. Российская Федерация патент RU 2328230. 10 июля 2008 г. [Chuchunov A.A., Levenets A.A., Krikun S.V., Nikolayev O.V., Bobkova O.V., authors. Krasnoyarsk State Medical Academy, assignee. Sposob operativnogo lecheniya razlitykh $i$ gnilostnonekroticheskikh flegmon dna polosti rta. Russian Federation patent RU 2328230. 2008 July 10 (in Russ.)]

7. Тайсинг Ю., Реттингер Г., Вернер Й.А., под ред. Хирургия головы и шеи: основные вмешательства. Москва: Лаборатория знаний, 2019. 459 с. [Theissing J., Rettinger G., Wemer J.A., editors. Head and neck surgery: basic interventions. Moscow: Laboratoriya znaniy, 2019. 459 p. (in Russ.)]
8. Arujuna N.R., Brendling L., DeGiovanni C. Dermatology surgery and reconstruction photograph booklet as a tool to improve informed consent before skin surgery. Dermatol Surg. 2018; 44(8):1070-1074. DOI: 10.1097/DSS.0000000000001519

9. Diamantis S., Giannakopoulos H., Chou J., Foote J. Descending necrotizing mediastinitis as a complication of odontogenic infection. International fournal of Surgery Case Reports. 2011; 2:65-67. DOI: 10.1016/j.ijscr.2011.01.004

10. Mervyn S., Clifford S.D., Christopher W.S., Manu S.H., Djillali A., Michael B., Rinaldo B. et al. The Third International Consensus Definitions for Sepsis and Septic Shock (Sepsis-3). JAMA. 2016; 315(8):801-810. DOI: $10.1001 /$ jama.2016.0287

11. Sung Y.H., Hee K.O., Jae Y.R., Jin J.K., Jin Y.C., Hyeon M.K. Closed suction drainage for deep neck infections. Fournal of Cranio-Maxillo-Facial Surgery. 2014; 42:751-756. DOI: $\underline{10.1016 / j . j \mathrm{cms} .2013 .11 .006}$

Поступила в редакцию 08.07.2019 Подписана в печать 19.09.2019

Для цитирования: Щенин А.В., Громов А.Л., Иванов С.В., Губин М.А., Артюшкова Е.Б. Обоснование применения модифицированного поднижнечелюстного доступа для вскрытия и дренирования одонтогенных флегмон дна полости рта. Курский научно-практический вестник «Человек и его здоровье». 2019; (3):46-55. DOI: 10.21626/vestnik/2019-3/07.

\title{
SUBSTANTIATION FOR USING MODIFIED SUBMANDIBULAR APPROACH FOR INCISION AND DRAINAGE OF ODONTOGENIC INFECTION OF THE MOUTH FLOOR
}

\author{
○ Shchenin A.V. ${ }^{1}$, Gromov A.L. ${ }^{1}$, Ivanov S.V. ${ }^{1}$, Gubin M.A. ${ }^{2}$, Artushkova E.B. ${ }^{1}$ \\ ${ }^{1}$ Kursk State Medical University (KSMU) \\ 3, K. Marx St., Kursk, Kursk region, 305041, Russian Federation \\ ${ }^{2}$ N.N. Burdenko Voronezh State Medical University (VSMU) \\ 10, Studencheskaya St., Voronezh, Voronezh region, 394036, Russian Federation
}

\footnotetext{
Objective: substantiation for the use of modified submandibular approach for treating odontogenic infection of the mouth floor.

Materials and methods. 62 patients were involved in this prospective study. The main group consisted of 30 patients with mean age 46.8 $\pm 11.8,16$ men (53.3\%), 14 women (46.7\%). Patients were treated with the modified submandibular approach with partial incision of the mandibulohyoid sac; the application for invention No. 2019118924, priority of 17.06.2019.

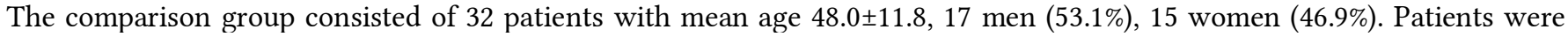
treated with the standard submandibular approach. The main group and the comparison group were comparable in age and sex ( $>0.05)$, the background pathology and antibacterial therapy.

Results. The modified approach allows to reduce the time of postoperative surgical site purification from $5.9 \pm 1.9$ days in the comparison group, in the main group up to $4.5 \pm 1.1$ days $(\mathrm{p}<0.05)$; granulation tissue from $5.1 \pm 2.0$ days in the comparison group, in the main group up to $3.7 \pm 1.0$ days $(\mathrm{p}<0.05)$; secondary suture application from $7.0 \pm 2.2$ days in the comparison group, in the main group up to $5.8 \pm 1.2$ days $(\mathrm{p}<0.05)$. There were no differences in the average bed days (the main group $8.2 \pm 0.9$ days, the comparison group $-9.0 \pm 2.1$ days, $\mathrm{p}>0.05)$ and the spread of the infection to adjacent organs $(1$ case in the main group, 3 cases in the comparison group, $p>0.05)$.

Conclusion. The modified method of treating odontogenic infection allows reducing the time of postoperative wound purification, and facilitating the appearance of granulation tissue and application of sutures.

Keywords: phlegmon; maxillofacial area; submandibular approach; odontogenic infection; local form of infection.

Shchenin Andrei V. - Post-Graduate Student of Department of Surgical Diseases N 1, KSMU, Kursk, Russian Federation. ORCID iD: 0000-0002-9746-7146. E-mail: schenin-92@mail.ru (correspondence author)

Gromov Aleksandr L. - PhD in Medicine, Associate Professor of Department of Surgical Dentistry and Maxillofacial Surgery, KSMU, Kursk, Russian Federation. ORCID iD: 0000-0002-4728-6451. E-mail: gromov.alexandr2011@yandex.ru

Ivanov Sergey V. - DM, Professor, Head of Department of Surgical Diseases N 1, KSMU, Russian Federation. ORCID iD: 0000-00022828-7424. E-mail: IvanovSV@kursksmu.net
} 
Gubin Mikhail A. - DM, Professor, Professor of the Department of Dentistry, VSMU, Voronezh, Russian Federation. E-mail: natasable@yandex.ru

Artyushkova Elena B. - Doctor of Biology, Professor of Department of Pharmacology, KSMU, Kursk, Russian Federation. ORCID iD: 0000-0003-3777-6622. E-mail: eartyushkova@mail.ru

\section{CONFLICT OF INTEREST}

The authors declare the absence of obvious and potential conflicts of interest related to the publication of this article.

\section{SOURCE OF FINANCING}

The authors state that there is no funding for the study.

\section{CONFORMITY WITH THE PRINCIPLES OF ETHICS}

The research protocol has been approved by the Regional ethics committee protocol no. 11 of the session of the Regional ethics committee of 10.12.2018. Participants of the study have signed the informed consent before being enrolled in the study.

\section{AUTHORS CONTRIBUTION}

Shchenin A.V., Gromov A.L. - data analysis and interpretation. Ivanov S.V. - development of the concept and design of the article, substantiation of the article and verification of critical intellectual content, final approval for the article publication. Gubin M.A. - development of the concept and design of the article, substantiation of the article and verification of critical intellectual content. Artushkova E.B. - development of the concept and design of the article.

Received 08.07.2019

Accepted 19.09.2019

For citation: Shchenin A.V., Gromov A.L., Ivanov S.V., Gubin M.A., Artushkova E.B. Substantiation for using modified submandibular approach for incision and drainage of odontogenic infection of the mouth floor. Kursk Scientific and Practical Bulletin "Man and His Health". 2019; (3):46-55. DOI: 10.21626/vestnik/2019-3/07. 